\title{
Notes on the vocalizations of Plumbeous Pigeon (Patagioenas plumbea)
}

Peter Boesman

In the following we briefly analyze and compare voice of the different races of Plumbeous Pigeon (Patagioenas plumbea). We also try to quantify the extent of any vocal differences using the criteria proposed by Tobias et al. (2010), as a support for taxonomic review. We have made use of sound recordings available on-line from Xeno Canto (XC).

Vocal differences among several races of Plumbeous Pigeon have been noted in a variety of sources over several decades, but to our knowledge a vocal comparison of all races in any type of detail has never been performed to date.

We have analyzed some 250 recordings available on XC and (making abstraction of recordings of the call note, a rolling "rrruw"), we can discern five vocal groups. An overview illustrated with sonograms:

\section{Group1 : $\mathbf{W}$ of Andes and lowland region $\mathbf{N}$ of river Amazon and $\mathbf{W}$ of rio Negro}

Phrase consists of three notes: a short usually upslurred note, a long pause, a short underslurred note, a short pause and a long bisyllabic note (more or less concatenated). This last note is about 3 times as long as the previous note.

Darien, Panama

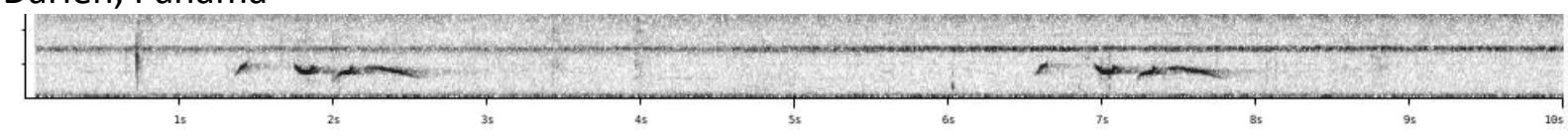

NW Colombia

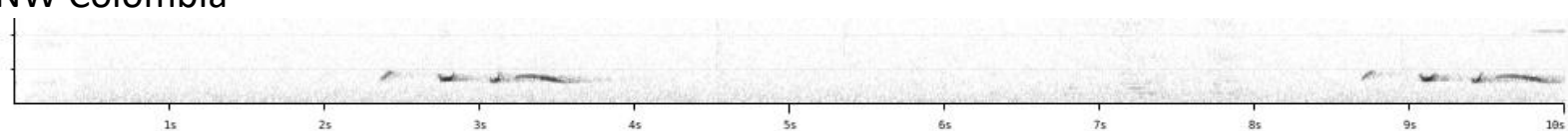

NW Venezuela

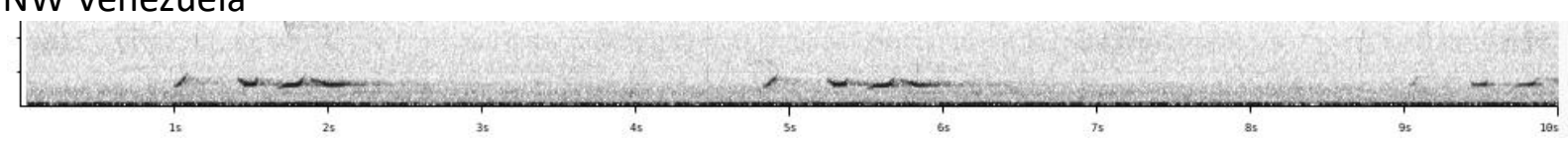

W Ecuador

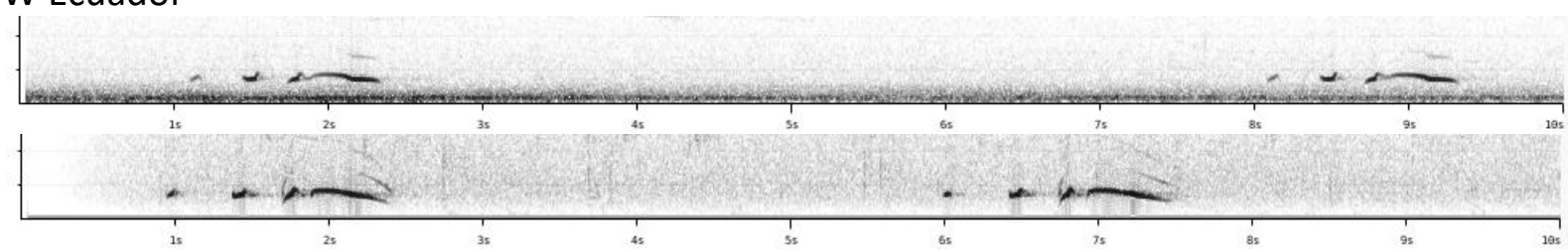

E Ecuador

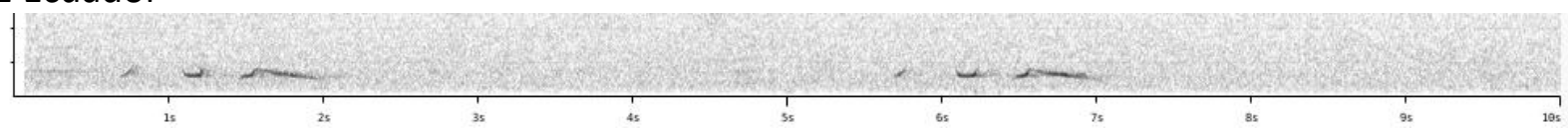

SE Ecuador

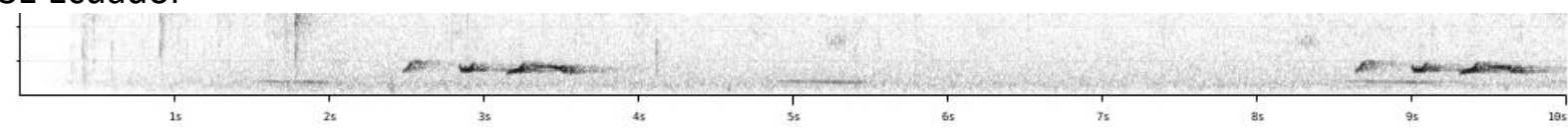




\section{HANDBOOK OF THE \\ BIRDSPIJUE WORLD}

\section{ORNITHOLOGICAL NOTES}

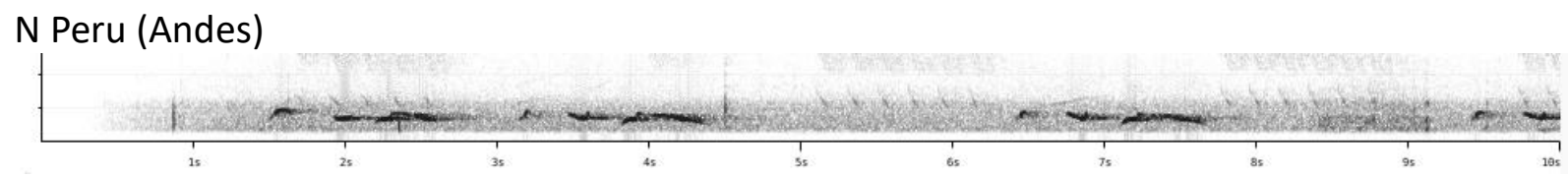

NE Peru (N of Amazon)

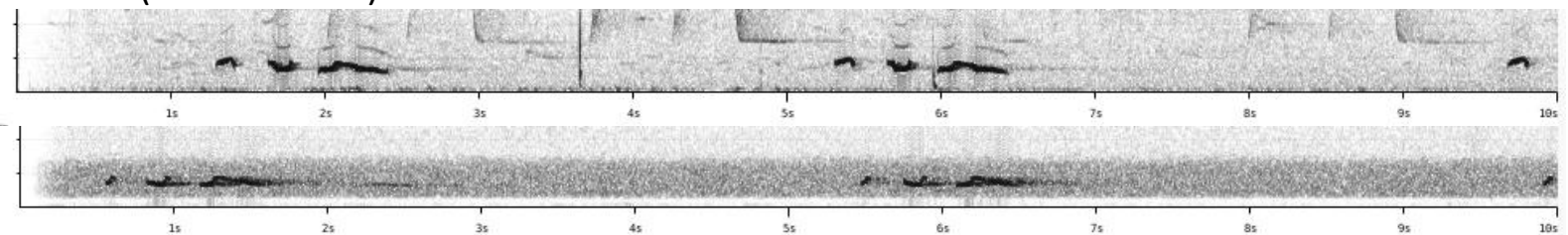

Manaus area W of rio Negro

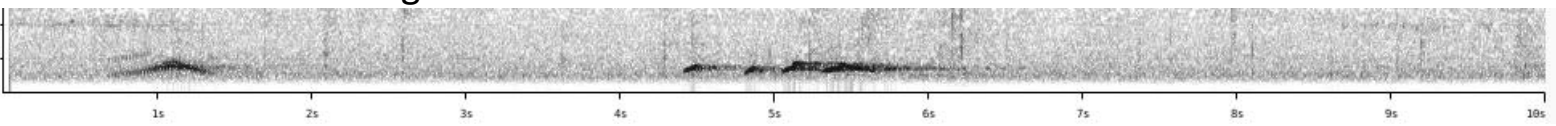

\section{Group 2: SE Amazon and Peruvian Andes}

Phrase consists of three notes: a short usually upslurred note, a pause, a longer (curled) note, a pause and a final curled note which is only slightly longer than the previous note. NE Peru (Tarapoto)
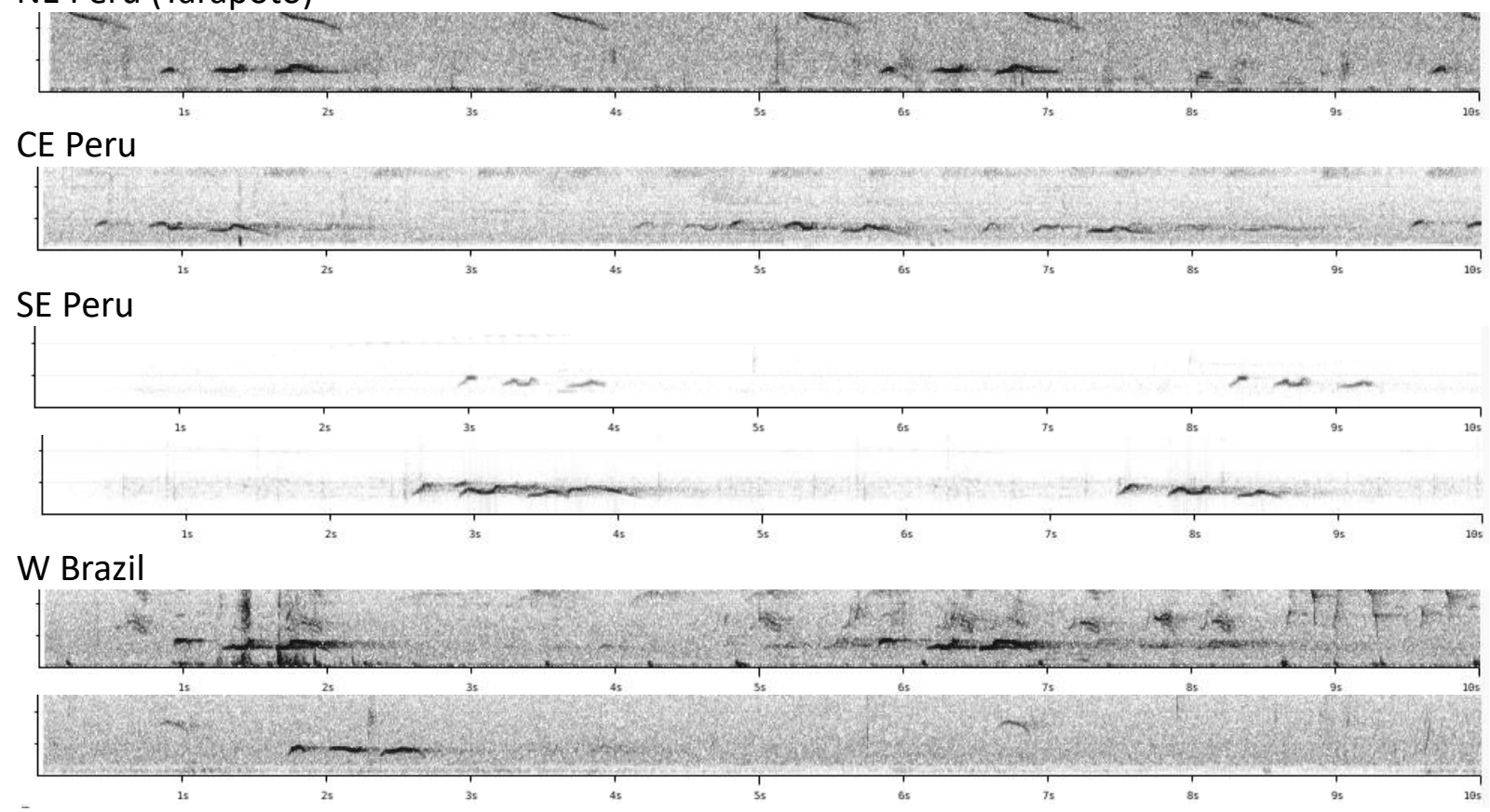

\section{E Bolivia}

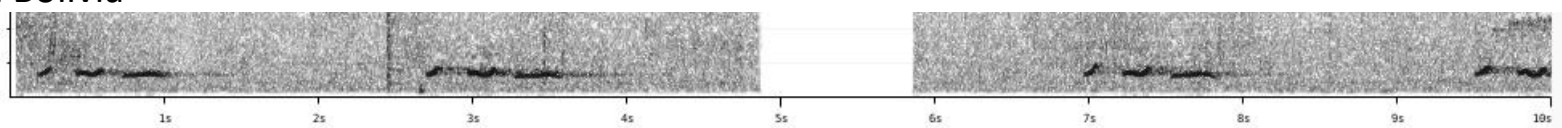

N Mato Grosso (Cristalino)SE Amazon

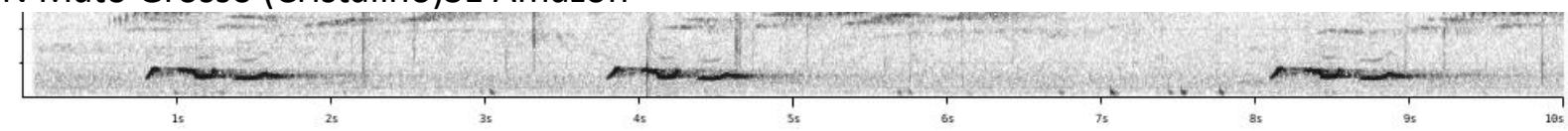




\section{HANDBOOK OF THE \\ Birof Alve}

\section{ORNITHOLOGICAL NOTES}

\section{Group 3: Yungas region}

Phrase consists of two notes: a short overslurred note, a pause and a long (curled) note. Total phrase length shortest of all groups (less than 1s).

Extreme S Peru (Andes)

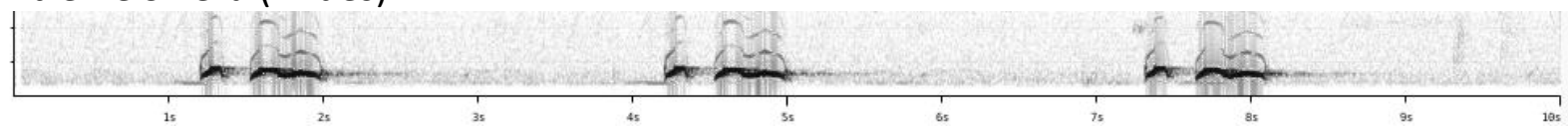

La Paz area

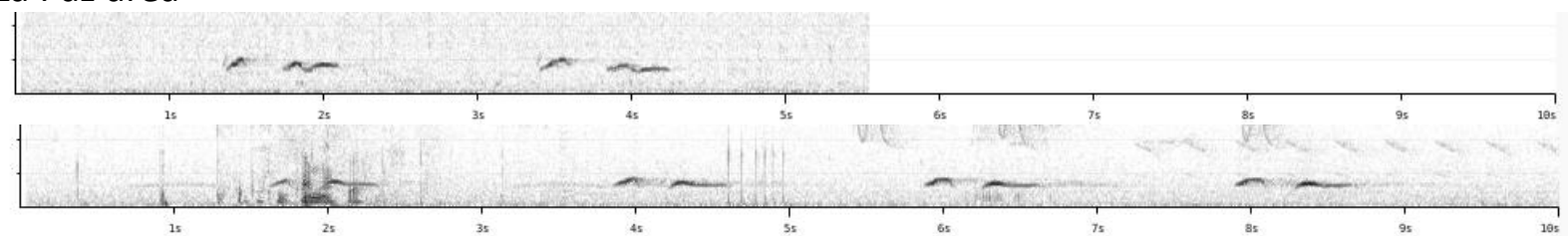

Cochabamba area

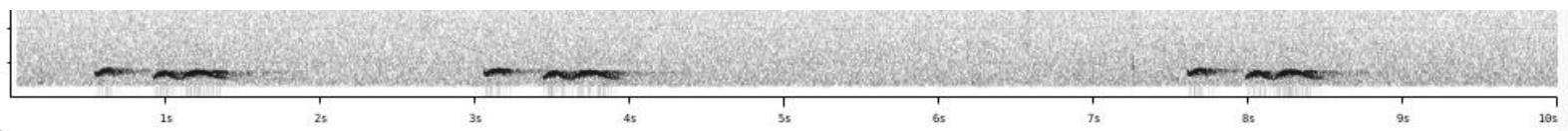

Santa Cruz area

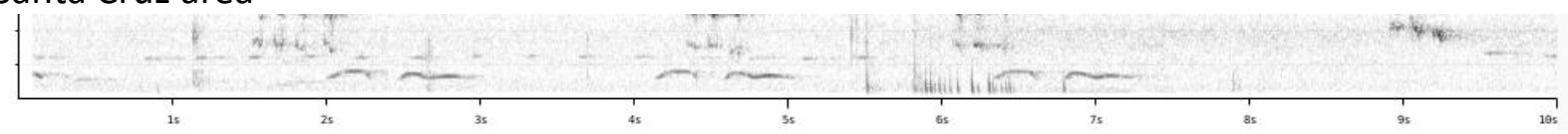

Group 4: Guianas and SE Amazon E of rio Madeira

Phrase consists of 4 notes: three short upslurred notes of which the first is followed by the longest pause and the second note is the shortest, and ending with a long final note SE Venezuela

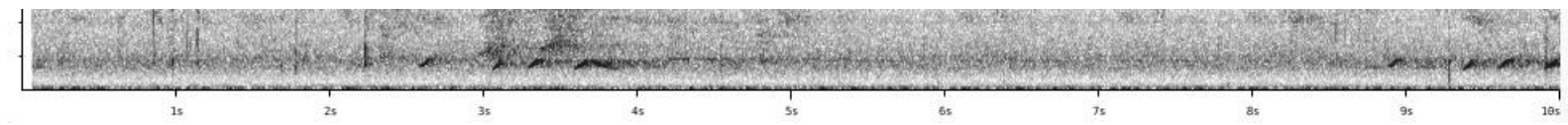

Suriname

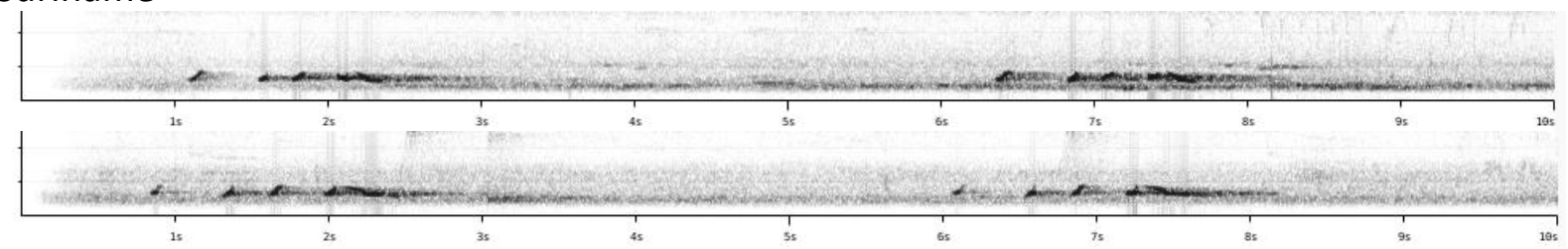

French Guyana

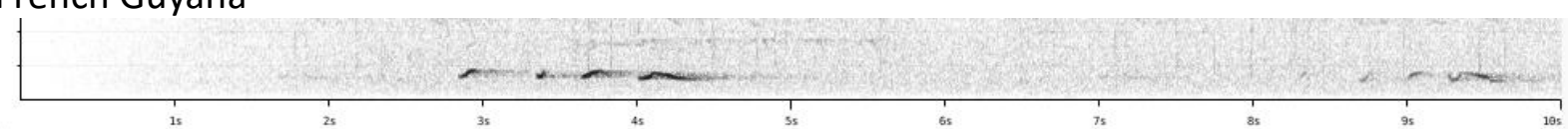

$\mathrm{N}$ of Manaus, Brazil

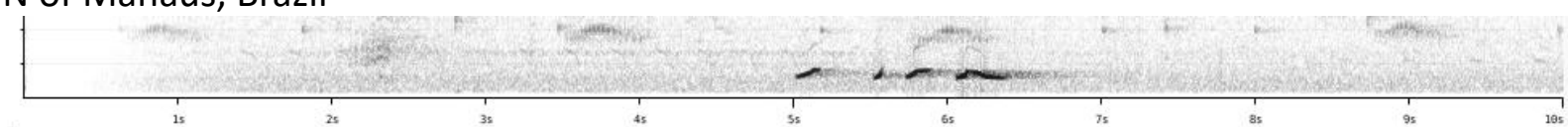

W Para

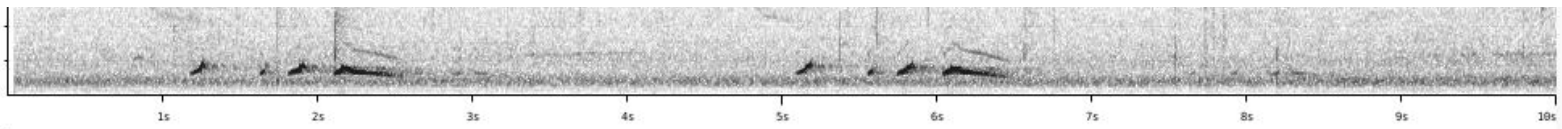




\section{HANDBOOK OF THE \\ BIRDSPF THE WORLD Alve}

\section{ORNITHOLOGICAL NOTES}

\section{Group 5: SE Brazil}

Phrase consists of 5 notes: 4 short underslurred notes of which the first is followed by the longest pause, and a long final note. Total phrase length about $2 \mathrm{~s}$ (longest of all groups).

SE Brazil

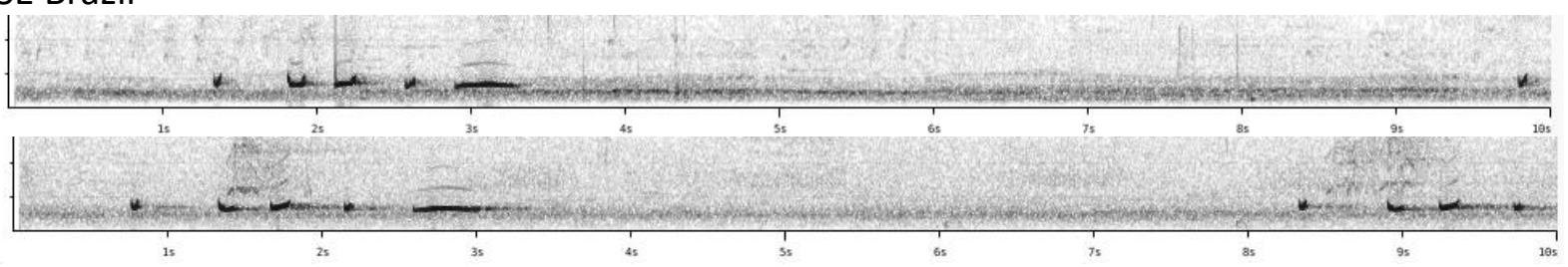

Goias

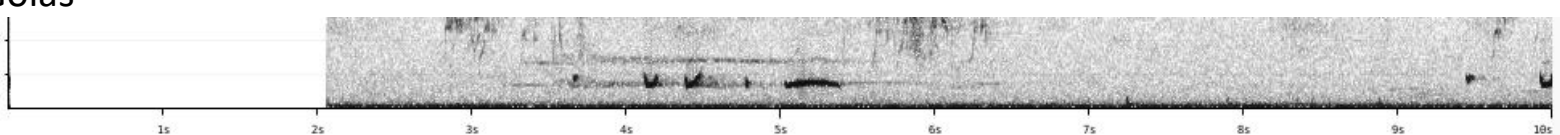

Salvador (slightly different, more recordings needed from this area)

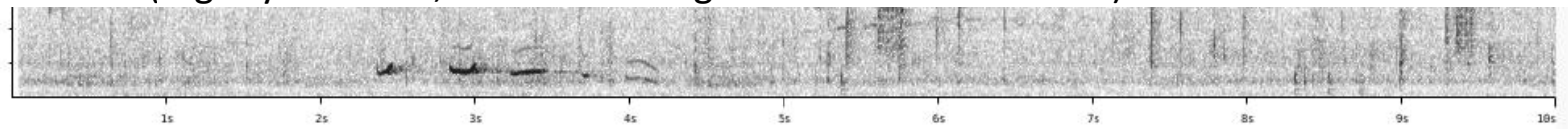

These five groups show geographically as follows:

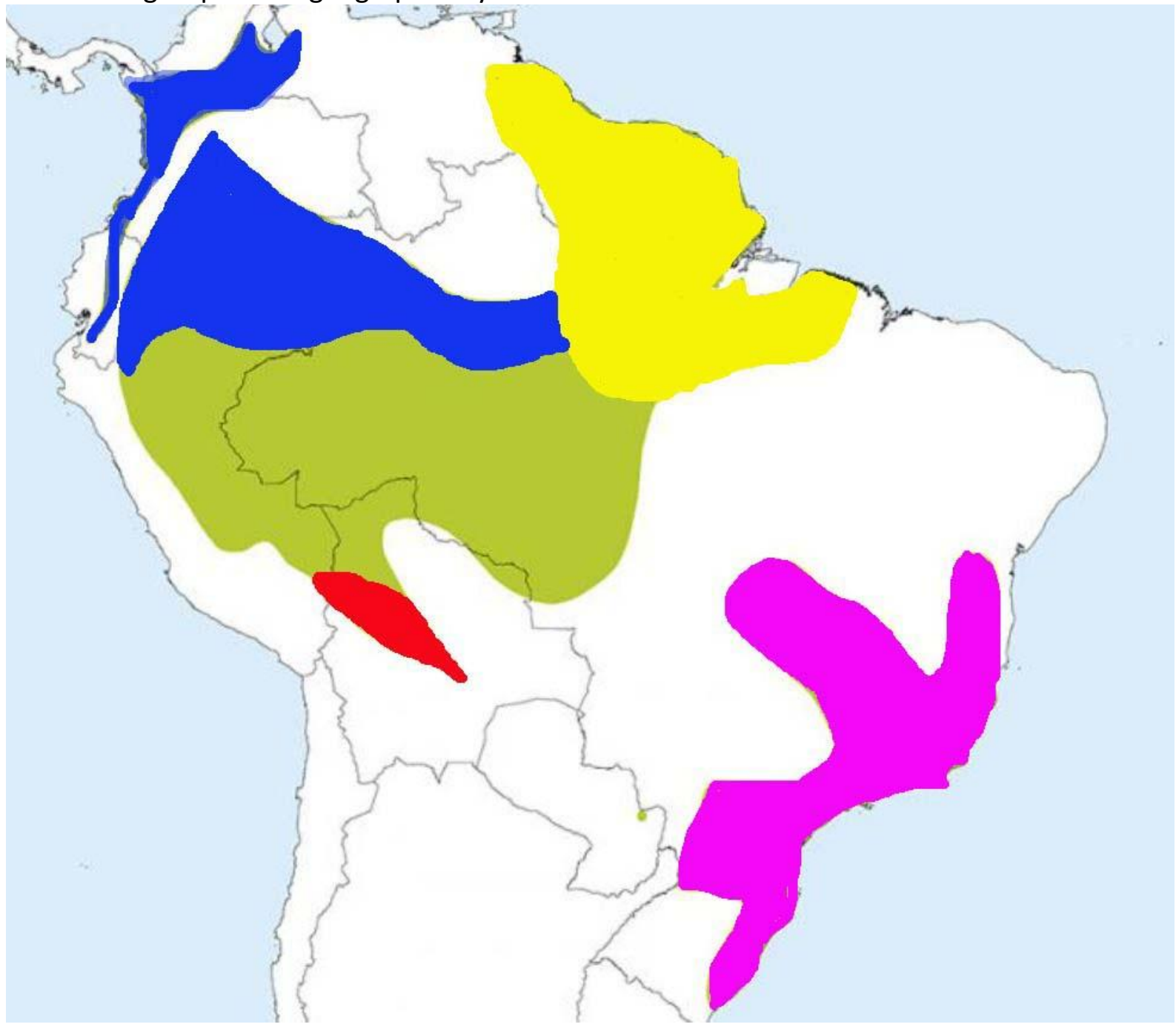



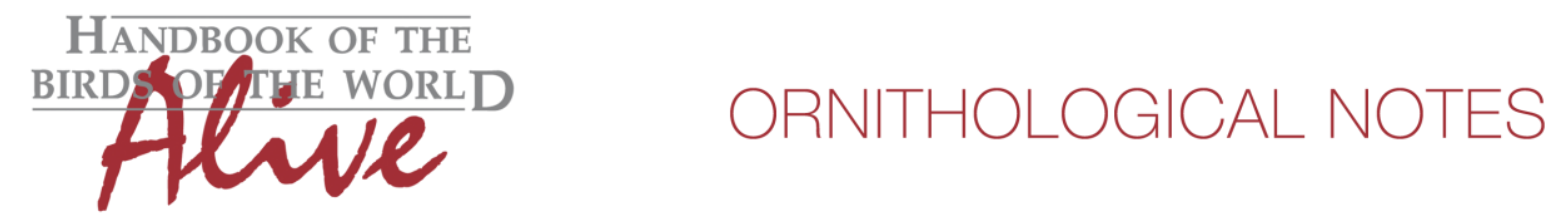

In the Andes of N Peru there may be a transition zone between group 1 and 2 . The Yungas population seems to be parapatric with group 2 while demonstrating a sudden change in voice (although XC92491 documents possibly an intermediate voice). Other groups are separated by geographical barriers (Rio Negro, Rio Amazon, Rio Madeira), although there are very few recordings in several parts of the Amazonian region. All these regions would benefit from additional recordings to test the robustness of this division in vocal groups.

Except for group 1 and 2, the differences of all groups are quite obvious (and a multivariate statistical analysis of a larger set of sound parameters may reveal several more differences, both temporal and frequency-related, as we haven't even looked into the latter).

$\begin{array}{lcl} & \text { Number of notes } & \text { Phrase length } \\ \text { Group } 1 \text { and } 2 & 3 & \text { c } 1.1-1.5 \mathrm{~s} \\ \text { Group } 3 & 2 & \text { c } 0.8 \mathrm{~s} \\ \text { Group } 4 & 4 & \text { c } 1.5-1.8 \mathrm{~s} \\ \text { group 5 } & 5 & \text { c } 2.0 \mathrm{~s}\end{array}$

The differences between group 1 and 2 are more subtle, and need more detailed parameters to describe differences, but e.g. the ratio of duration of the two last notes is about 3 in Group 1 and less than 2 in group 2 (with possibly some slight overlap), the first pause duration of group 1 is significantly longer than group 2 etc.

A more in depth analysis with detailed measurement of a large set of sound parameters is recommended to reach a better quantification of all vocal differences.

It is clear however from this preliminary analysis that a vocal score by application of Tobias criteria for groups 3,4 and 5 could be in the range of 4-6 based on number of notes and phrase length a.o. parameters.

The 5 global groups only partially coincide with the 6 recognized races:

Group 1: chapmani and bogotensis in part

Group 2: bogotensis in part and pallescens (in part?)

Group 3: bogotensis in part

Group 4: wallacei

Group 5: plumbea and baeri

Given that plumage differences are very subtle, it is quite likely that the present taxonomic treatment should be revised, and ultimately it would be an even stronger signal for taxonomic revision if genetic analysis further confirms the groups as defined by vocal differences (although at the other hand vocal analysis of another pigeon complex, in which vocal differences were far more subtle and available recordings far less numerous, has led to the acceptance of several splits by some taxonomic authorities, see $\mathrm{Ng}$ et al. 2016).

This note was finalized on 12th January 2017, using sound recordings available on-line at that moment. We would like to thank in particular the many sound recordists who placed their recordings for this species on XC. 


\section{References}

Ng, E., Eaton, J., Verbelen, Ph., Hutchinson, R. \& Rheindt, F. (2016). Using bioacoustic data to test species limits in an Indo-Pacific island radiation of Macropygia cuckoo doves. Biol J. Linn. Soc.

Tobias, J.A., Seddon, N., Spottiswoode, C.N., Pilgrim, J.D., Fishpool, L.D.C. \& Collar, N.J. (2010). Quantitative criteria for species delimitation. Ibis 152(4): 724-746.

\section{Recommended citation}

Boesman, P. (2017). Notes on the vocalizations of Plumbeous Pigeon (Patagioenas plumbea). HBW Alive Ornithological Note 446. In: Handbook of the Birds of the World Alive. Lynx Edicions, Barcelona. (retrieved from http://www.hbw.com/node/1323564 on 12 January 2017). 